\title{
Development of Small and Large Intestine
}

\author{
Mukaddes EŞREFOĞLU' ${ }^{1}$, Aslı ÇETIN ${ }^{2}$ \\ 'Department of Histology and Embryology, Bezmialem Vakıf University School of Medicine, İstanbul, Turkey \\ ${ }^{2}$ Department of Histology and Embryology, İnönü University School of Medicine, Malatya, Turkey
}

\begin{abstract}
Epithelial components of the organs of the digestive system are derived from endoderm whereas connective tissue and muscle components are derived from mesoderm. At the $3-4^{\text {th }}$ of development, as a result of cephalocaudal and lateral foldings of the embryo, a portion of the endoderm-lined yolc sac cavity is incorporated in the embryo to from the primitive gut. Primitive gut is composed of four main regions which are pharyngeal gut, foregut, midgut, and hindgut; respectively. Intestines are derived from foregut, midgut and hindgut. The development of the intestines is characterised by lengthening, widening, thickening, histological and positional changes. In this manuscript we tried to review the morphological and functional development of the small and large intestines with the aid of pictures obtained from various stages of prenatal and postnatal development the intestines of rats. Previous reviews lack of information on both histological and functional development of the small and large intestines.
\end{abstract}

Keywords: Development, large intestines, small intestines

\section{Bowel Histology}

The intestinal wall consists of the mucosa, submucosa, muscularis (muscularis externa), and adventitia layers. The mucosa consists of epithelium, lamina propria, and muscularis mucosa. The epithelium of intestinal mucosa of both small and large intestines is simple columnar in type. The epithelium contains tall columnar absorptive cells and musuc sectering goblet cells. In the small intestines, the mucosa and the submucosa are folded to form the villi. The lamina propria as a loose connective tissue is largely occupied by tubular intestinal glands. Glands of the small intestines contain paneth cells, enteroendocrine cells, $\mathrm{M}$ cells, and stem cells in addition to enterocytes and goblet cells

Glands of the large intestines of healthy individuals do not contain paneth cells. The muscularis mucosa, which is the last layer of the mucosa, is composed of two smooth muscle layers that are circular interiorly and longitudinal exteriorly. The submucosal nerve plexus (Meissner nerve plexus) is found in the medium-density connective tissue of the submucosa. In the duodenum, there are seromucous glands known as Brunner glands in this layer. The tunica muscularis is composed of two layers of smooth muscle consisting of an inner circular and outer longitudinal layer in the small intestine. The myenteric nerve plexus is located between the muscle layers. In large intestines, outer longitudinal coat of the muscularis is not a complete layer and is present as three longitudinal bands, so it is observed as an incomplete layer in cross sections. The outermost layer is serosa $(1,2)$.

\section{The Development of Primitive Intestine}

With the growth and letaral and cefalocaudal folding of the embryo in the third to fourth weeks of development, a part of yolk sac lined by endoderm remains in the embryo body, resulting in the formation of a primitive intestine. The primitive intestine is composed of four parts: the pharyngeal gut, the foregut, the midgut, and the hindgut. The pharyngeal gut is separated from the stomodeum by the buccopharyngeal membrane. At the end point of the hindgut, the cloacal mem- 
brane that separates this segment from the surface ectoderm is located (3-11).

The pharyngeal gut extending between the buccopharyngeal membrane and the tracheobronchial diverticulum is characterized by the pharyngeal arches, clefts, and pouches. Five pairs of endoderm-lined pharyngeal pouches give rise to the middle ear cavity, auditory tube, tympanic membrane (from the first pair), palatine tonsils (from the second pair), thymus and lower parathyroid glands (from the third pair), upper parathyroid glands (from the fourth pair), and parafollicular cells of the thyroid gland The subsequent foregut extends to the bottom of the liver bud. The respiratory system, esophagus, stomach, proximal part of the duodenum, liver, pancreas, and bile duct develop from this part. The subsequent midgut extends from the bottom of the liver bud to the end point of the two-thirds of proximal part of the transverse colon. Therefore, the distal jejunum, ileum, cecum, appendix, ascending colon, and $2 / 3$ proximal part of the transverse colon develop from this region. The remaining distal part of the transverse colon, the descending colon, the sigmoid colon, and the rectum develops from the hindgut that is the last part of the primitive intestine $(3-5,7,8)$.

\section{Further Development of the Intestines}

The intestines develop from the foregut, midgut or hindgut related with their anatomical regions. The duodenum develops from the distal part of the foregut and from the proximal part of the midgut. The junction of these two parts is located just below the liver bud (7). The duodenum grows rapidly, creating a forward C-shaped curve. During the rotation of the stomach, the duodenal loop turns rightand enters into the retroperitoneal region (3-9). The midgut extends from from the opening point of the ductus choledochus into the duodenum, to the junction of $2 / 3$ proximal and $1 / 3$ distal parts of the transverse colon $(5,7,12)$. The midpoint of the midgut just coincides with the middle of the ileum. The distal part of the duodenum and the proximal part of the jejunum and ileum develop from the cephalic part; the distal part of the ileum, cecum, appendix, ascending colon, and $2 / 3$ proximal part of the transverse colon develop from the caudal part $(3-10,12)$. The junction of the cranial and caudal loops can be detected by the presence of vitelline duct remnants called "Meckel's diverticulum" or "ileal diverticulum" $(7,8)$.

The subsequent development of the primary intestinal loops is characterized by rapid lengthening, especially in the cephalic limb. The volume of the expanded gut tract and of liver and kidneys is greater than the body cavity can accommodate. Consequently, the developing intestines are herniated into the extra-embryonic coelom cavity (umbrical cord) at 6 weeks of gestation. This is called "physiological umbilical herniation" $(3,7-9)$. The herniated intestinal loops begin to move through the abdominal cavity at about $9^{\text {th }}$ week. It is suggested that regression of mesonephros, deceleration in the growth rate of the liver, and the enlargement of the abdomi- nal cavity might be the triggering factors of the the intestinal return (3-9). This phenomenon is defined as the "contraction of the herniation of the midgut." The proximal part of the jejunum returns first and locates in the central part of the the abdominal cavity. The other intestinal loops returning within a short time are positioned to the right side of the previously located loops $(5,7,9)$. The cecal bulge, which appears as a conical enlargement from the caudal part of the primitive intestinal loop when the embryo is $12 \mathrm{~mm}$, is the last intestinal segment returning to the abdominal cavity $(7,9)$. The cecum then descends to the right iliac fossa by forming the ascending colon and hepatic flexure. In the meantime, a narrow diverticulum called the "primitive appendix" appears at the distal end of the cecal bulge $(3,5,7,8)$.

As the primitive intestinal loop elongates, it rotates around the axis of the superior mesenteric artery. The rotation reaches to counterclockwise 270 degrees when it is completed as viewed from in front. The midgut rotation continues during the herniation period (the first 90 degrees) and during the retraction of the midgut to the abdominal cavity (the remaining 180 degrees) $(3-8,12)$.

The distal $1 / 3$ of the transverse colon, the descending colon, the sigmoid, the rectum, and the upper part of the anal canal develop from the hindgut. The bladder epithelium and a large part of the urethra arise from the hindgut (3-9). The cloaca is divided into two parts by a mesenchymal septum called the urorectal septum. The septum separates the cloaca into two parts as the cranial compartments of the rectum and anal canal, and the urogenital sinus (3-7). At the seventh week, the urorectal septum separates the cloaca membrane into the dorsal anal membrane and the ventral urogenital membrane. The anal membrane ruptures at the end of the eighth week and allows the distal part of the anal canal to be connected with the amniotic space (3-6).

In mammals, the epithelium of the digestive system develops from the embryonic endoderm whereas the muscles, hematopoietic elements, and connective tissue develop from the mesoderm. The interaction between the epithelium and the mesenchyme plays a crucial role in the development of the intestines (13). It has been demonstrated that the endoderm of the primitive foregut does not further differentiate in the cultures devoid of mesodermal tissues (14). The intestinal canal begins to acquire its characteristic fetures as the mesoderm grows, thickens and differentiates into smooth muscles (15). The development of intestines requires the growth, rotation and translocation of primitive intestinal loops, and acquire its charcteristic histological features $(7,10)$. Rapid cellular proliferation in the endoderm and mesenchyme provides prolongation of the intestinal tract, formation of the lumen, and formation of the crypt-villus axis (13).

Villi, epithelium, and glands: Villi develop at the duodenum at first as a result of the proliferation of mesenchymal tissue beneath the epithelium (9). Villi appear at the ninth week as 

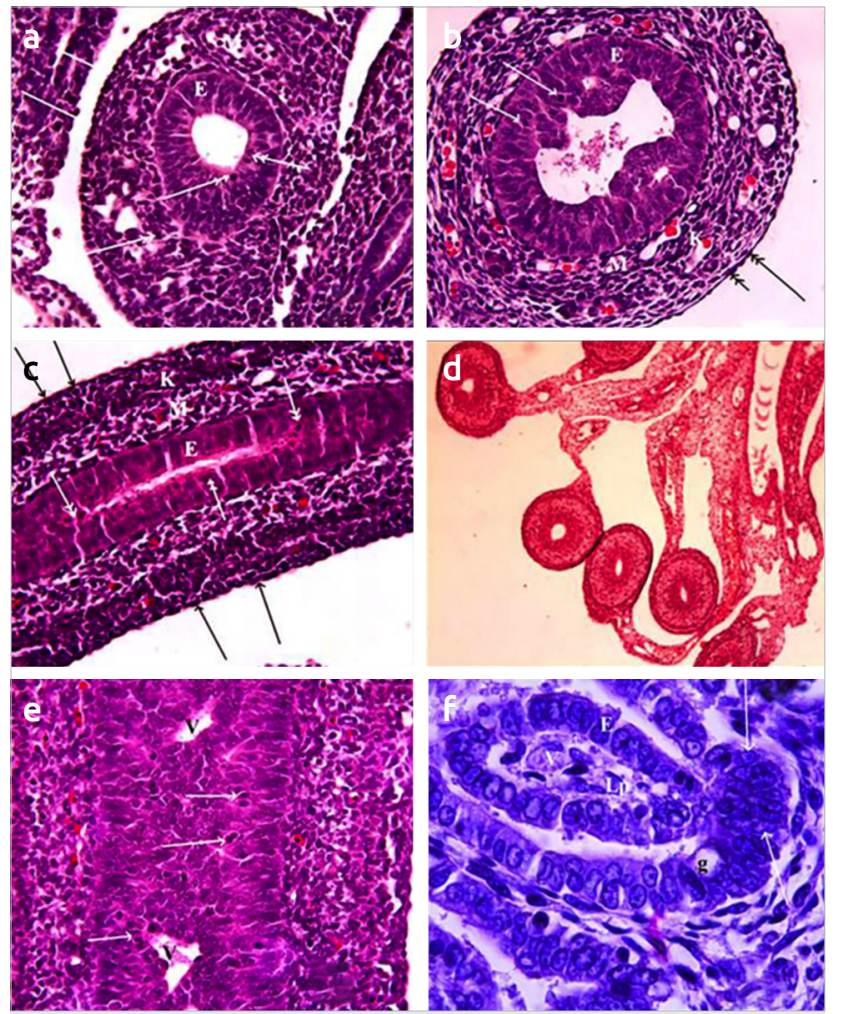

Figure 1. a-f. The intestinal changes of a rat in the prenatal period are shown. (a) On I.U. day 7, it is observed that the wall of the intestine consists of stratified columnar epithelium (E) and mesenchymal connective tissue (M), that the intestine is externally lined with single-layered squamous epithelium (arrows), and the epithelium and connective tissue include many mitosis figures (twoheaded arrows). Large and small intestines cannot be differentiated in this period. H-E; X 40. (b) On I.U. day 10 , it is viewed that intestinal lumen is narrowed by stratified columnar epithelium (E), which is occasionally very thick, and a circular muscle layer appears in the mesenchymal connective tissue (M) extending under the epithelium. Note that there are vacuoles (v) within the epithelium, frequent mitosis figures (white arrows), and a single-layered epithelium that externally surrounds the intestinal wall (black, two-head arrows). Large and small intestines cannot be differentiated in this period. H-E; X 40. (c) On I.U. day 14, it is still observed that stratified columnar epithelium (E) partially obstructs the lumen. In this period, muscle tissue (M) in the mesenchymal connective tissue $(M)$ is thickened. Mitosis figures in the epithelium (white two-head arrows) and a squamous epithelium lining the intestinal wall externally (black arrows) are marked. Large and small intestines still cannot be differentiated in this period. H-E; $X$ 40. (d, e) On I.U. day 17, some of intestinal loops are observed out of the abdominal wall. In rats, physiological intestinal herniation occurs in a later period, imminent to delivery, compared with human beings. In this period, it is still viewed that thick, stratified columnar epithelium partially obstructs the lumen and the vacuoles (V) locally open the lumen. Mitosis figures, which are frequently seen in the epithelium, are marked with arrows. H-E; X 10, H-E; X 40. (f) On I.U. day 20 , it is seen that the epithelium (E) gains single-layered columnar characteristic, and goblet cells (g) appear in the epithelium and the epithelium and underlaying lamina propria form the villi $(V)$. Condensation of cells in the base of the villus (arrows) indicates the beginning of the formation of the glands. In this period, villi are seen in both large and small intestine. H-E; X 100.
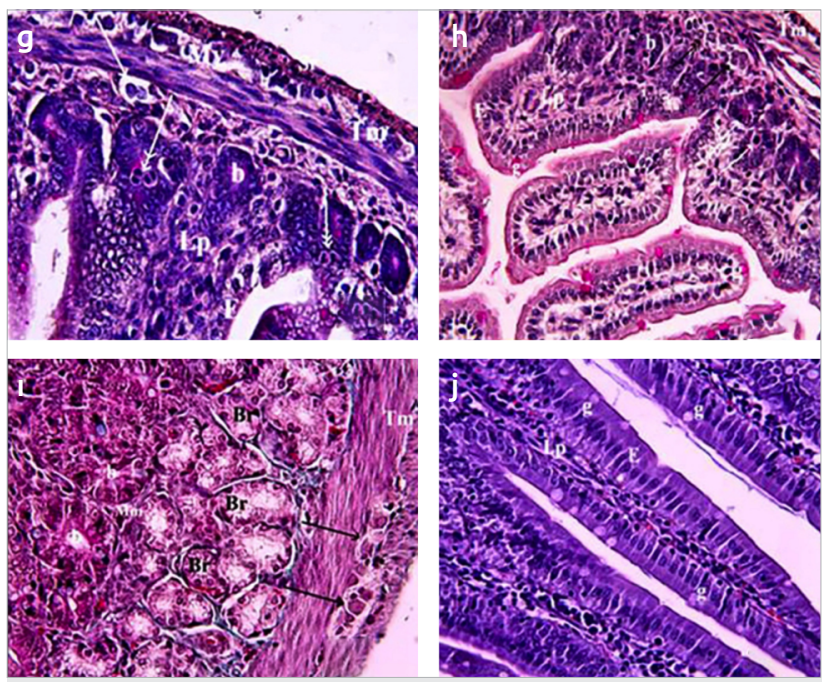

Figure 1. g-j. The changes in the duodenum in the postnatal period are viewed. (g) On the postnatal fifth day, epithelium (E), lamina propria (LP), tunica muscularis $(\mathrm{Tm})$, and serosa $(\mathrm{Sr})$ layers are seen. The glands can be recognized although they are short $(\mathrm{g})$ and muscularis mucosa can be recognized, although it is not clear. There are Meissner nerve plexus (arrow) in the submucosa layer, myenteric plexus (My) between muscle layers, and frequent mitosis figures in the epithelium (two-head arrows). On the postnatal 10th day, epithelium (E) including PAS+ stained goblet cells $(\mathrm{g})$ and displaying striated border, lamina propria (Lp), tunica muscularis (Tm) and serosa layers are seen. The glands ( $g$ ) seem to be longer and Meissner nerve plexus (black two-head arrows) seem to be widespread. Mitosis figures in the epithelium are marked (white arrows). PAS; X 40. (l) On the postnatal 15th day, intestinal glands (b), muscularis mucosa (Mm), Brunner glands (br) specific to the submucosa of the duodenum, two-layered, thickened tunica muscularis (Tm), and extensive myenteric plexus between muscle layers (arrows) are observed. Masson's trichrome staining method; $X$ 40. (j) The longer villi consisting of lamina propria (LP) and epithelium (E) including goblet cells are observed in young adult. $H-E ; X 40$.

a result of the infiltration of the mesenchymal tissue beneath the multi-layered surface epithelium. . During this episode, the surface epithelium transformes into one-layer columnar epithelium (16-18). Primitive glands appear in the small intestines at I.U. weeks 9-12 in human beings (19). Brunner glands develop from the bottom of these crypts in the duodenum. In the large intestines, crypts and villi occur at the same time. The part between the two large intestinal villi matchs to the crypts of Lieberkühn. The villi that also appear in the large intestine during the development disappear as the villus tips thicken (9). The villi of the colon are wide and flat (20). The lower parts of the villi and the area between to adjacent villi become permanent crypts (9). The small and large intestines cannot be distinguished from each other at I.U. week 7.5 in human beings (21). Intestinal development also continues after birth. The length of the villus in human beings increases after birth and reaches adult size at the fourth week (22).

The intestinal epithelium has an appearance of a stratified or 


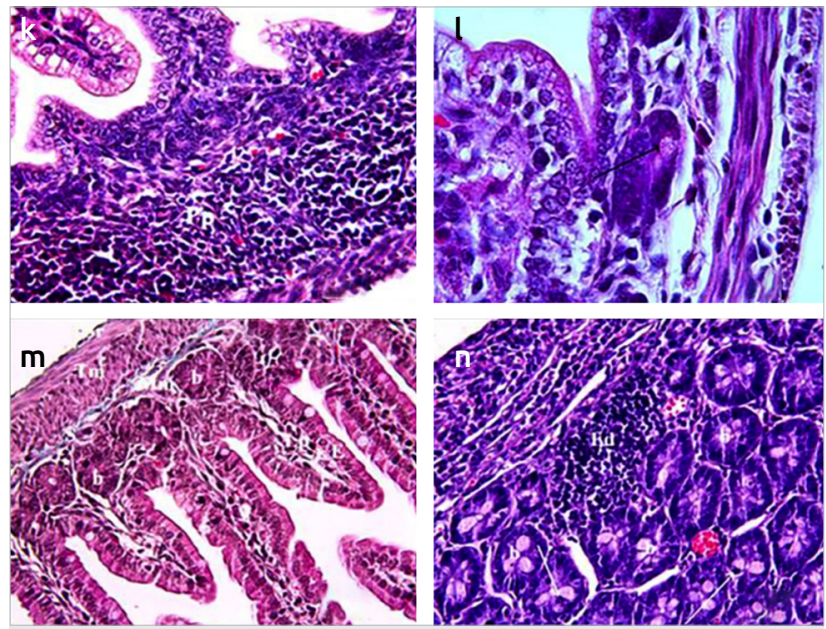

Figure 1. k-n. The changes in the ileum in the postnatal period. (k) On the postnatal fifth day, Peyer plaques (Pp) are observed. On the postnatal 10th day, Paneth cells (arrow) with acidophil cytoplasm are seen in the glandular epithelium. H-E; X 100. (m) On the postnatal 15th day, it is viewed that villi (V) consisting of epithelium (E) and lamina propria (LP) are extended, the glands $(g)$ in the lamina propria are more apparent, histological features of muscularis mucosa $(\mathrm{Mm})$, submucosa $(\mathrm{S})$, tunica muscularis $(\mathrm{Tm})$, and serosa (Sr) layers begins to be similar to those of the adults. Masson's trichrome staining method; X 20. (n) Lymphoid tissue is denser at the bottom of the lamina propria in young adult. H-E; X 40.

a pseudo-stratified epithelium for some time during the development. The intestinal lumen is completely or partially occluded as a result of the excess proliferation of epithelial cells due to frequent mitosis about I.U. week 5 . Then, the lumen is recanalized by the fusion of the vacuoles that emerge in I.U. week 6-7. However, Grand et al. (23) observed intraepithelial vacuoles within the $10^{\text {th }}$ week of gestation in human beings $(7,10)$. It has been suggested that the vacuoles begin to appear in the lower parts of the epithelium next to the basal membrane and fuse to reform a central lumen. Initial formation of a vacuole is thought to be associated with epithelial apoptosis (12). Villi and glands appear during recanalization. In this period, stratified epithelium differentiates into a single-layer columnar epithelium. At the end of I.U. $6^{\text {th }}$ month, all of the cell types of the glands can be seen $(7,10)$. However, different results have been reported about the periods of appearance of glandular cells. Morikawa et al. (24) have observed duodenal glands containing PAS positive material after birth and reported that following nursing the glandular cells actively secrete. It has been reported that there is an increase in the duodenal glands until the end of the postnatal second month and that the cells are filled with secretory material (25).

Goblet cells: Goblet cells begin to appear after I.U. week 8 (19). These cells have been shown to increase in number 19-fold beginning from the birth to the $24^{\text {th }}$ day. This result suggests that nursing may have an inducing effect on the number of goblet cells (26). Paneth cells begin to appear in I.U. weeks 11-12 $(19,27)$.
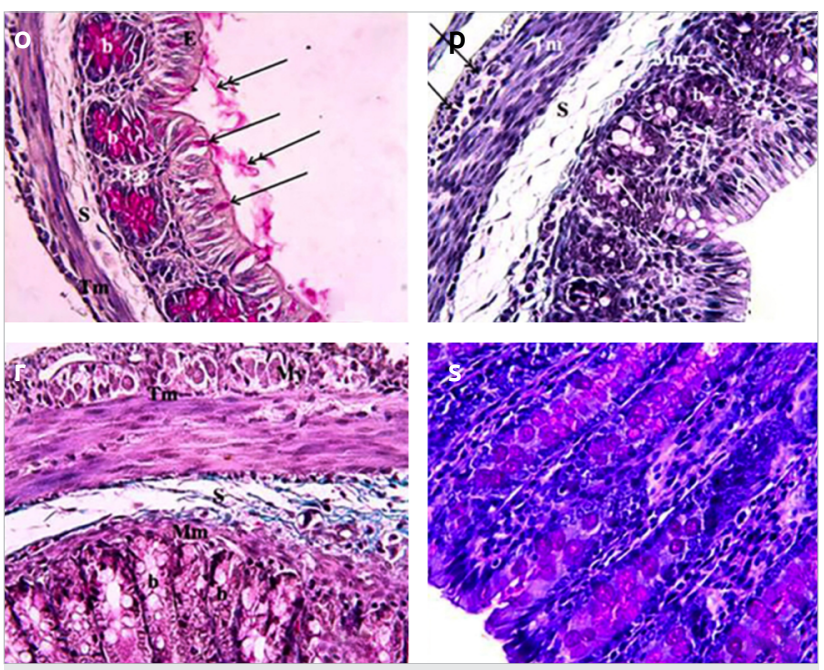

Figure 1. o-s. The changes in the colon in the postnatal period are observed. (o) On the postnatal fifth day, stratified columnar epithelium (E), lamina propria (Lp), muscularis mucosa, submusoca (S), tunica muscularis (Tm), and serosa layers are obvious. Note that mucus on the surface (two-head arrows) and mucus in the cytoplasms of goblet in the surface epithelium and in the gland $(g)$ epithelium are stained with PAS+ (single-head arrows). PAS; X 40. (p) On the postnatal 10th day, all layers are thickened. There are myenteric plexus between the muscle layers of tunica muscularis (black arrows) and frequent mitosis figures in the gland epithelium (white arrows). Masson's trichrome staining method; $X$ 40. (r) On the postnatal 15th day, it is seen that glands $(g)$ are extended, muscularis mucosa (Mm), submucosa (S), and tunica muscularis (Tm) are thickened, and myenteric plexus (My) in muscle layers is more widespread. Masson's trichrome staining method; $X$ 40. (s) Long intestinal glands are viewed in the thickened lamina propria in young adult. It draws attention that the epithelium is single-layered columnar and there are many goblet cells in the surface and gland epithelium in this period. PAS; $X 40$.

Enteroendocrine cells: Enteroendocrine cells appear in the I.U. 9-1 $1^{\text {th }}$ weeks (19). Numerous endocrine cells are seen in the duodenum and rectum in I.U. $7-12^{\text {th }}$ weeks and in the ileum and colon in the I.U. 24-25 ${ }^{\text {th }}$ weeks (28).

Muscularis mucosa: The muscularis mucosa develops at the end of the fourth month $(8,9)$.

Muscularis externa: As of the second month, the circular muscles of the intestines appear first in the duodenum and then, in the small intestines, in the large intestines and rectum, respectively. Longitudinal muscles are formed in I.U. $10-12^{\text {th }}$ weeks $(8,9)$. The electron microscopic features of the small intestine muscles in an 18-week-old fetus were found the same as those of adult muscles (29). Peristaltism in the small intestines begins as of I.U. week 12 (30). The migration of neuroblasts that will form the myenteric plexus begins in small intestines at I.U. $5^{\text {th }}$ week and extends to the rectum at the $12^{\text {th }}$ week $(31)$. At the $18^{\text {th }}$ week, neuroblasts and mature ganglion cells are seen in the myenteric plexus (32). 
Functional maturation of the digestive system in human beings begins at a quite early stage in the first period of gestation but progresses rather slowly (33). Actually, the entire morphological and functional organization of the crypt-villus axis (including its digestive capacity) bears close resemblance to the newborn and adult mucosa at I.U. 18-20 ${ }^{\text {th }}$ weeks (16-18). The system of a newborn is capable of digesting carbohydrates and proteins in addition to the nutrients obtained from milk (33). It has been reported that the colon is structurally and functionally similar to the small intestine during the newborn period and that the mucosa is flattened and stops secreting digesting enzymes a few days following birth (34-36). Figure 1 summarizes the change in the intestines during the prenatal and postnatal development in a rat.

Peer-review: Externally peer-reviewed.

Author Contributions: Concept - M.E., A.Ç.; Design - M.E., A.Ç.; Supervision - M.E., A.Ç.; Funding - M.E.; Materials - M.E.; Data Collection and/or Processing - M.E.; Analysis and/or Interpretation - M.E.; Literature Review - M.E.; Writing - M.E.; Critical Review - M.E.

Conflict of Interest: No conflict of interest was declared by the authors.

Financial Disclosure: No conflict of interest was declared by the authors.

\section{References}

1. Eşrefoğlu M. Özel Histoloji. 2. Baskı, İstanbul: İstanbul Tıp Kitabevi; 2016.

2. Ross MH, Pawlina W. Histology. A Text and Atlas. 6th Ed. Philadelphia: Lippincott Williams and Wilkins; 2011.

3. Moore KL, Persaud TVN. Klinik yönleri ile İnsan Embriyolojisi. (M. Yıldırım, İ. Okar, H. Dalçık, Çev.). 1. baskı, İstanbul: Nobel Matbaacilık; 2002.

4. Şeftalioğlu, A. Genel \& Özel İnsan Embriyolojisi. 3. baskı, Ankara: Tıp \& Teknik Yayıncılık Ltd. Şti, 1998.

5. Moore KL, Persaud TVN. Embriyoloji ve doğum defektlerinin temelleri. (S. Müftüoğlu, P. Atilla, F. Kaymaz, Çev.). 7. Baskı, İstanbul: Güneş Tip Kitabevleri; 2009.

6. Schoenwolf GC, Bleyl SB, Brauer PR, Francist-West PH. Larsen's Human Embryology. 4 th ed. Philadelphia: Churchill Livingstone; 2009.

7. Sadler TW. Langman's Medikal Embryology. 6. ed., Philadelphia: Williams and Wilkins; 2006.

8. Petorak İ. Medikal Embriyoloji. İstanbul: Beta Basım Yayım Dağıtım; 1984.

9. Kayalı H, Şatıroğlu G, Taşyürekli M. İnsan Embriyolojisi. 7. Baskı, İstanbul: Alfa Basım Yayım Dağıtım, 1992.

10. Carslon BM. Human embryology and developmental biology. 4th. ed. Philadelphia: Mosby Elsevier; 2009.

11. Gregersen H, Lu X, Zhao J. Physiological growth is associated with osephageal morphometric and biomechanical changes in rats. Neurogastroenterol Motil 2004; 16: 403-12. [CrossRef]

12. Larsen W. Development of the gastrointestinal tract. In: Sherman LS, Potter SS, Scott WJ, eds. Human Embryology, 4th ed. Philadelphia: Churchill Livingstone, 2009; 435-77.

13. Rubin DC. Intestinal morphogenesis. Curr Opin Gastroenterol 2007; 23: 111-4. [CrossRef]

14. Koike T, Yasugi S. In vitro analysis of mesenchymal influences on the differentation of stomach epithelial cells of the chicken embryo. Differentiation 1999; 65: 13-25. [CrossRef]

15. Roberts DJ. Molecular mechanisms of development of the gastrointestinal tract. Developmental Dynamics, 2000; 219: 109-20. [CrossRef]
16. Menard D. Growth-promoting factors and the development of the human gut. In Human Gastrointestinal Development (Ed. E Lebenthal). New York: Raven Press; 1989; 123-49.

17. Menard D, Beaulieu JF. Human intestinal brush border membrane hydrolases. In Membrane Physiopathology (Ed. G. Bkaily). Kluwer Academic, Norwell, 1994; 319-41. [CrossRef]

18. Menard D, Calvert R. Small and large intestinal fetal and postnatal development: patterns and regulation. In Growth of the Gastrointestinal Tract: Gastrointestinal Hormones and Growth Factors (Eds. T. Salomon and J. Morrisset). CRC Press, Boca Raton 1991; 147-62.

19. Tamiolakis D, Venizelos J, Lambropoulou M, Nikolaidou S, Bolioti S, Tsiapai M, Verettas D, Tsikouras P, Chatzimichail A, Papadopoulos N. Human embryonal epithelial cells of the developing small intestinal crypts can express the Hodgkin-cell associated antigen Ki-1 (CD30) in spontaneous abortions during the first trimester of gestation Theor Biol Med Model 2005; 2: 1. [CrossRef]

20. Barbara PS, van den Brink GR, Roberts DJ. Development and differentiation of the intestinal epithelium. Cell. Mol. Life Sci 2003; 60: 1322-32. [CrossRef]

21. Rigoard P, Haustein SV, Doucet C, Scepi M, Richer JP, Faure JP. Development of the right colon and the peritoneal surface during the human fetal period: human ontogeny of the right colon. Surg Radiol Anat 2009; 31: 585-9. [CrossRef]

22. Cheng H, Bjerknes M. Whole population cell kinetics and postnatal development of the mouse intestinal epithelium. Anat Rec 1983; 211: 420-6. [CrossRef]

23. Grand RJ, Watkins JB and Torti FM. Progress in gastroenterology: Development of the human gastrointestinal tract - a review. Gastroenterology 1976; 70: 790-810.

24. Morikawa Y, Miyamoto M, Okada T. Perinatal development of Brunner's glands in the rat: morphometrical study. Biol Neonate 1993; 63: 258-67. [CrossRef]

25. Krause WJ, Leeson CR. The origin, development and differentiation of Brunner's glands in the rat. J Anat 1976; 101: 309-20.

26. Cummins AG, Steele TW, Labrooy JT, Shearman DJ. Maturation of the rat small intestine at weaning: Change in epithelial cell kinetics, bacterial flora and mucosal immunite activity. Gut, 1988; 29: 1672-9. [CrossRef]

27. Moxey PC, Trier JS. Specialized cells types in the human fetal small intestine. Anat Rec 1978; 191: 269-86. [CrossRef]

28. Lolova IS, Davidoff MS, Itzev DE. Histological and immunocytochemical data on the differentiation of intestinal endocrine cells in human fetus. Acta Physiol Pharmacol Bulg 1998; 23: 61-71.

29. Benedeczky I, Fekete E, Resch B. Ultrastructure of the developing muscle and enteric nervous system in the small intestine of human fetus. Acta Physiol Hung 1993; 81: 193-206.

30. Stach W. A revised morphological classification of neurons in the enteric nervous system. In: Singer MV, Goebell H, eds., Nerves and the gastrointestinal tract. Kluwer Academic Publishers, Lancester, 1989: 29.

31. Okamoto E, Ueda T. Embryogenesis of inramural ganglia of the gut its relation to Hirschprung disease. J Pediatr Surg 1967; 2: 437-41. [CrossRef]

32. Fekete E, Resch BA, Benedeczky I. Histochemical and ultrastructural features of the developing enteric nervous system of the human fetal small intestine. Histol Histopathol 1995; 10: 127-134.

33. Sangild PT. Gut Responses to Enteral Nutrition in Preterm Infants and Animals. Exp Biol Med 2006; 231: 1695-711.

34. Halender HF. Morphological studies on the development of the rat colonic mucosa. Acta Anat 1973; 85: 153-76. [CrossRef]

35. Foltzer-Jordainne C, Kedinger M, Raul F. Perinatal expression of brush border hydrolases in rat colon: hormonal and tissular regulations. Am J Physiol 1989; 257: G496-G503.

36. Freund JN, Duluc I, Foltzer-Jourdainne C, Gosse F, Raul F. Specific expression of lactase in the jejenum and colon during postnatal development and hormone treatments in the rat. Biochem J 1990; 268: 99103. [CrossRef] 